\section{Case Reports in Oncology}

\title{
Metachronous Development of Meningothelial Meningioma, Basal Cell Carcinoma, and Glioblastoma Multiforme in a Patient with Pancreatic Incidentaloma
}

\author{
Emanuil Naydenov ${ }^{a} \quad V^{2}$ ceslav Bussarsky ${ }^{a} \quad K^{\prime}$ stadin Angelov ${ }^{b}$ \\ Marin Penkov ${ }^{c}$ Sevdalin Nachev ${ }^{d}$ Savina Hadjidekova ${ }^{e}$ \\ Draga Toncheva ${ }^{\mathrm{e}}$ \\ aDepartment of Neurosurgery, University Hospital "St. Ivan Rilski", Sofia, Bulgaria; \\ ${ }^{b}$ Department of General Surgery, University Hospital "Alexandrovska", Sofia, Bulgaria; \\ 'Department of Radiology, University Hospital "St. Ivan Rilski", Sofia, Bulgaria; ${ }^{\text {d Laboratory }}$

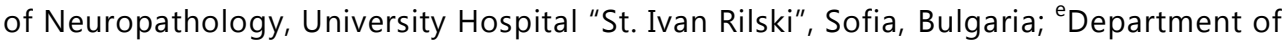 \\ Medical Genetics, Medical University, Sofia, Bulgaria
}

\section{Keywords}

Pancreatic incidentaloma · Meningothelial meningioma - Glioblastoma multiforme ·

Basocellular carcinoma

\begin{abstract}
We report the unique case of a 61-year-old male patient with known pancreatic incidentaloma who additionally developed 3 other histologically different tumors: left sphenoid wing meningothelial meningioma, basal cell carcinoma of the occiput, and right occipital lobe glioblastoma multiforme. The latter were totally removed with a favorable clinical outcome. The patient's family history was unremarkable, and no data on any previous head and neck irradiation were found.


 Oncology}

\section{Introduction}

The presence of multiple primary brain tumors of different histological type in association with other somatic neoplasms is extremely rare, with only a few cases described in the literature. We report on a patient with known pancreatic incidentaloma (PI) who additionally developed 3 other histologically different lesions: left sphenoid wing meningothelial meningioma (MMG), basal cell carcinoma (BCC) of the occiput, and right occipital lobe glioblastoma multiforme (GBM).

\section{Case Report}

A 61-year-old male patient with an unremarkable family history and known PI (Fig. 1) was referred to our clinic with short-term complaints of speech disturbances and progressive weakness of his right extremities. The magnetic resonance imaging (MRI) demonstrated a complex space-occupying process localized in the left temporopolar region (Fig. 2a). A total removal of the tumor was performed using an extended pterional approach. The histological examination revealed an MMG (WHO grade I; Fig. 3a). The patient recovered well after the intervention and was scheduled for regular follow-up (Fig. 2b). No additional radiotherapy was performed. Two years later, the patient was operated on because of a persistent nonhealing skin ulcer of the occiput. A radical excision of the lesion was made. The histological result was consistent with that of a BCC (Fig. 3b). No further treatment was administered following the intervention. One year later, the patient was readmitted with a 1-month history of progressive disorientation and gait and visual disturbances. The MRI demonstrated a heterogeneous right occipital lobe tumor (Fig. 2c). A gross-total removal of the lesion was performed using intraoperative contrast enhancement with Fluorescein Na (Fig. 2d). The histological and microarray studies revealed the typical picture of a primary GBM (WHO grade IV; Fig. 3c, d, Fig. 4). The patient recovered well and underwent adjuvant chemoradiation in standard doses and regimens. No data on any tumor recurrences were found on the subsequent neuroimaging studies (Fig. 2e, f).

\section{Discussion}

The exact incidence of PIs in the general population is unknown. Moreover, with the widespread availability and improved quality of abdominal imaging procedures, the number of these findings has been progressively increasing during the last few decades. According to some authors, PIs are usually solid, with an overall malignancy rate of $24.0 \%[1,2]$. In our case, the lesion was detected in the course of an abdominal computed tomography scan, and the patient refused any further intervention because of the lack of specific complaints.

The occurrence of a pancreatic tumor in combination with intracranial meningioma $(\mathrm{MG})$ is rare but seems not to be accidental, especially in the cases with a benign pathology. In 2004, Asgharian et al. [3] published a prospective study of 74 patients with known multiple endocrine neoplasia type 1 syndrome. In all cases, a histologically proven or suspected pancreatic endocrine tumor was also present. During the mean follow-up period of 7.2 years, MG occurred in 6 of the patients (8\%). One of the resected intracranial tumors demonstrated loss of heterozygosity at 11q13 and 1p, including ARH1/NOEY2 locus, thus giving the authors grounds to assume that impaired function of the MEN1 gene plays an important role in 


\section{Case Reports in Oncology}

the pathogenesis of the disease [3]. In our case, no clinical data on any endocrine disorder were present, and the exact diagnosis of PI was not histologically verified. The MMG was found independently, 1 year after the abdominal lesion, because of the appearance of specific neurological complaints.

Gorlin syndrome is a rare hereditary disorder characterized by a predisposition to early BCC occurrence due to a dominant PACH1 gene mutation (9q22.3). According to Xie et al. [4] (1997) and Sina-Frey et al. [5] (2003), in these patients, a high incidence of MGs and pancreatic carcinomas may also be present. However, in our case, the family history was unremarkable and the onset of the cutaneous disease was late, thus making the possible diagnosis of Gorlin syndrome rather uncertain.

The presence of multiple primary brain tumors of different histological types in one patient is relatively rare. However, some cases have been described occasionally in the literature. The most frequently reported combination is MG and glioma, followed by MG and neurinoma and by MG and pituitary adenoma [6, 7]. The following factors seem to deserve consideration in the search for an explanation of this phenomenon: a simple coincidence; genetic predisposition to multiple brain neoplasms; ionizing radiation; other environmental carcinogenic factors; surgical stress; production of tumor-stimulating substances by the initial neoplasm; and residual embryonic structures [6-8]. In our patient, the MMG and GBM occurred separately, in completely different areas of the brain, and no data on any previous head and neck irradiation were found.

Only a few cases of multiple primary brain tumors in association with other somatic malignant neoplasms have been published in the literature. In 1972, Sorenson [9] reported on a 69-year-old male patient harboring colorectal carcinoma, MMG, and malignant astrocytoma. Seven years later, Pöyhönen et al. [10] described the case of a female with breast cancer and 1 primary brain tumors of different histological type, MG and GBM. In 2003, Welsh et al. [11] reported on a patient with 5 synchronous neoplasms, including malignant thymoma, papillary thyroid cancer, metastatic adenocarcinoma of the colon, gliosarcoma, and MG. Recently, we also described another patient with colorectal carcinoma in association with pituitary adenoma and GBM [12]. All these cases seem to be more suggestive of an unknown type of multiple neoplasia syndrome or carcinogen exposure than a mere coincidence.

\section{Conclusion}

This is the first clinical report of a patient harboring PI in association with 3 other histologically different primary tumors of the head: MMG, BCC, and GBM. In spite of the favorable clinical outcome, the etiopathogenic basis of this phenomenon remains unclear and requires further investigation.

\section{Acknowledgement}

The authors wish to thank the Stay Foundation, Sofia, Bulgaria (www.stay.eu.com), for supporting this research project. 


\section{Statement of Ethics}

The authors have no ethical conflicts to disclose. Patient consent was graciously obtained for the publication needs.

\section{Disclosure Statement}

The authors declare that there are no conflicts of interest.

\section{References}

1 Bruzoni M, Johnston E, Sasson AR: Pancreatic incidentalomas: clinical and pathologic spectrum. Am J Surg 2008;195:329-332.

-2 Sachs T, Pratt WB, Callery MP, Vollmer CM Jr: The incidental asymptomatic pancreatic lesion: nuisance or threat? J Gastrointest Surg 2009;13:405-415.

- 3 Asgharian B, Chen YJ, Patronas NJ, Peghini PL, Reynolds JC, Vortmeyer A, Zhuang Z, Venzon DJ, Gibril F, Jensen RT: Meningiomas may be a component tumor of multiple endocrine neoplasia type 1 . Clin Cancer Res 2004;10:869-880.

-4 Xie J, Johnson RL, Zhang X, Bare JW, Waldman FM, Cogen PH, Menon AG, Warren RS, Chen LC, Scott MP, Epstein EH Jr: Mutations of the PATCHED gene in several types of sporadic extracutaneous tumors. Cancer Res 1997;57:2369-2372.

5 Sina-Frey M, Bartsch DK, Grundei T, Grützmann R, Rieder H: Pancreatic cancer and basal-cell carcinoma. Lancet 2003;361:180.

6 Russell DS, Rubinstein LJ: Tumours of the meninges and related tissues; in Russell DS, Rubinstein LJ (eds): Pathology of Tumours of the Nervous System, ed 5. Baltimore, MD, Williams \& Wilkins, 1989, pp 449-532.

7 Tokunaga T, Shigemori M, Hirohata M, et al: Multiple primary brain tumors of different histological types. Report on two cases. Neurol Med Chir 1991;31:141-145.

-8 Nestler U, Schmidinger A, Schulz C, et al: Glioblastoma simultaneously present with meningioma report of three cases. Zentralbl Neurochir 2007;68:145-150.

9 Sorenson BF: Multiple primary tumors of the brain and bowel. Case report. Neurosurg 1972;36:93-96.

10 Pöyhönen L, Heikkinen J, Vehkalahti I: Two different primary tumours of the brain in a patient with breast cancer. Eur J Nucl Med 1979;4:483-484.

11 Welsh JS, Thurman SA, Howard SP: Thymoma and multiple malignancies: a case of five synchronous neoplasms and literature review. Clin Med Res 2003;1:227-232.

12 Naydenov E, Marinov M, Nachev S: Two different primary brain tumors, glioblastoma multiforme and pituitary adenoma, in association with colorectal carcinoma: an unusual case of nonfamilial Turcot's syndrome? J Neurol Surg A Cent Eur Neurosurg 2012;73:410-412.

Unfortunately, Venceslav Bussarsky has deceased. 


\section{Case Reports in Oncology}
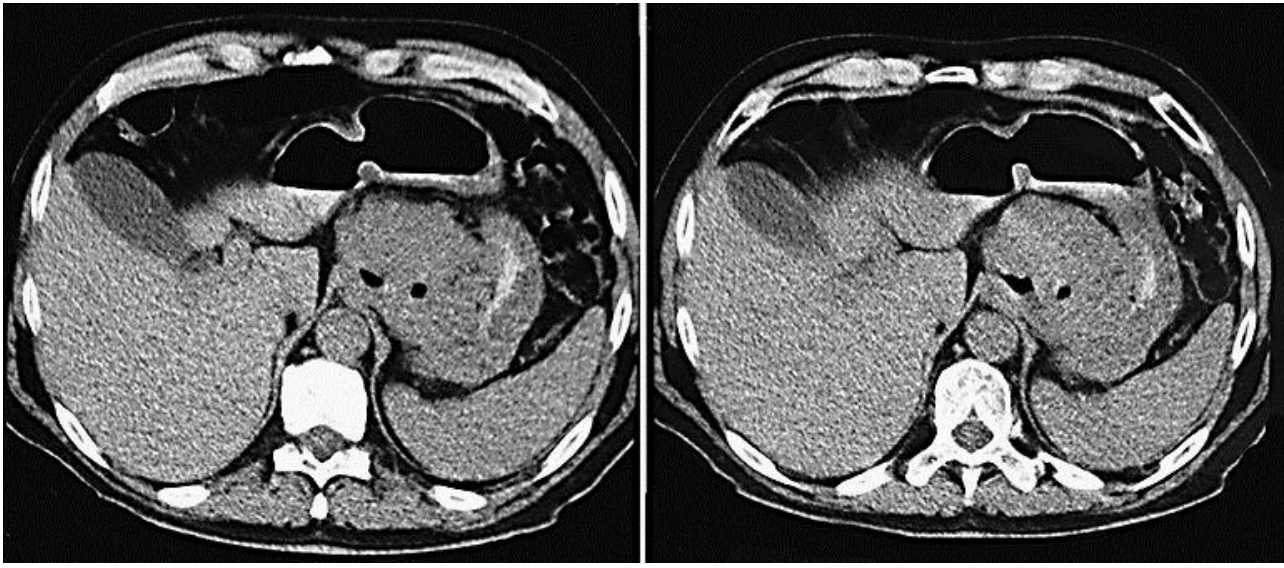

Fig. 1. Abdominal computed tomography scan of the patient: a solid mass which involves the pancreas at the area of the gastroduodenal junction can be seen.
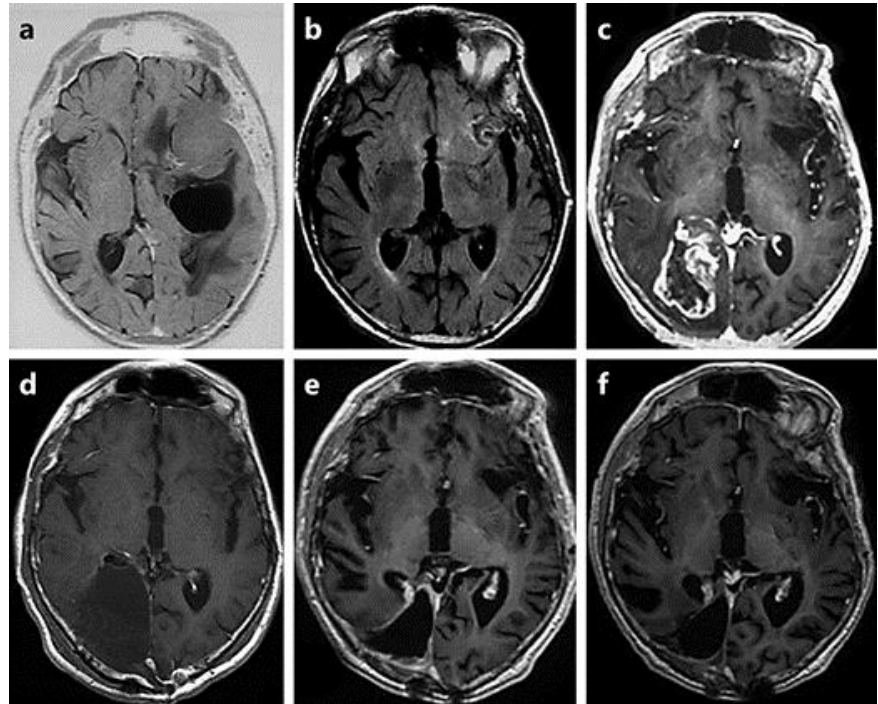

Fig. 2. Neuroimaging of the patient: conventional magnetic resonance imaging (MRI) scan before (a) and 6 months after (b) the removal of the left sphenoid wing meningothelial meningioma; contrast-enhanced MRI study before the gross-total excision of the right occipital lobe glioblastoma multiforme (c), on the next day (d), and at the sixth (e) and twelfth (f) month after the gross-total excision. 


\section{Case Reports in Oncology}
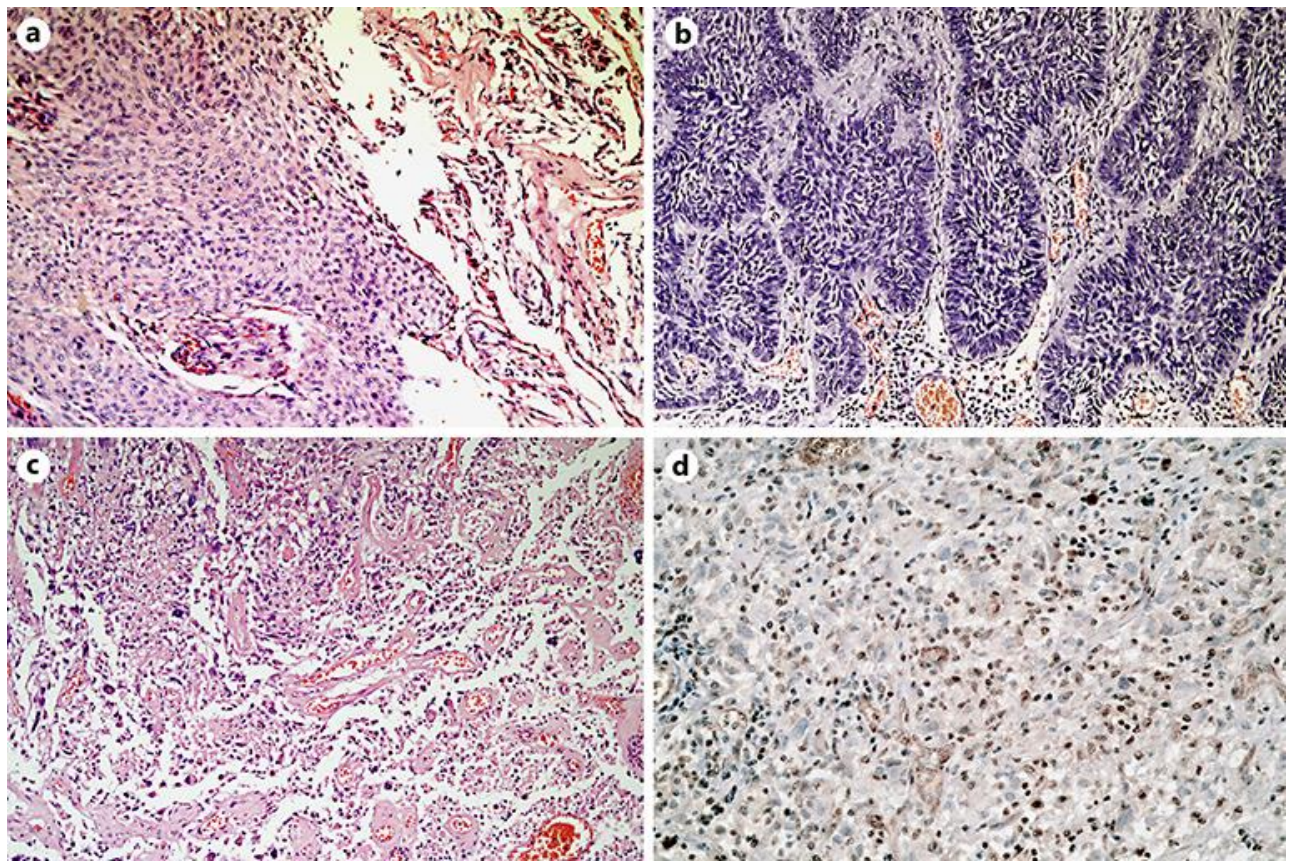

Fig. 3. Histological analyses of the different tumor samples: the sphenoid wing tumor (a) is composed of uniform cells with syncytial growth in sheets and lobules surrounded by thin stroma - meningothelial meningioma, WHO grade I (HE, $\times 100$ ); the cutaneous lesion (b) demonstrates proliferation of basaloid cells parallel to the long axis of the epidermis, and a slit-like stromal retraction with mucin deposition in the papillary dermis is also seen - a typical picture of a superficial basal cell carcinoma $(\mathrm{HE}, \times 100)$; the occipital lobe tumor (c) shows prominent cellular polymorphism, microvascular proliferation, and pseudopalisading necrosis - WHO grade IV glioma $(\mathrm{HE}, \times 100)$; immunohistochemical analysis of the glioblastoma multiforme sample (d) - scattered 0-6-methylguanine-DNA methyltransferase (MGMT)-positive cells are observed (MGMT, ×200).

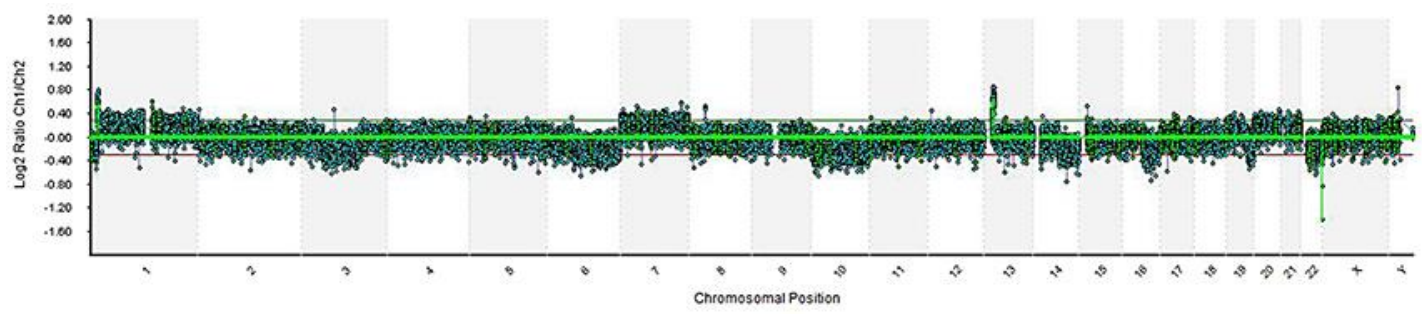

Fig. 4. DNA microarray analysis of the occipital lobe tumor revealed the following aberrations: trisomy 1,7 , 20, 21; monosomy 10, 22; deletions 3p21.31q21.31, 6q, 14q23.1qter, 16q12.2qter, 19q13.32qter; and gains $1 \mathrm{p} 36.21,13 \mathrm{q} 12.11$. 